\title{
Evaluation of different clean heat supply modes based on crop straws in the rural area of Northern China
}

\author{
Lili Huo ${ }^{1,2}$, Zonglu Yao ${ }^{1 *}$, Jixiu Jia', Lixin Zhao ${ }^{1,2}$, Hongbin Cong ${ }^{2}$, Haibo Meng ${ }^{2}$, Yanwen Yuan ${ }^{2}$ \\ (1. Institute of Environment and Sustainable Development in Agriculture, CAAS, Beijing 100081, China; \\ 2. Institute of Rural Energy and Environmental Protection, Academy of Agricultural Planning and Engineering, Key Laboratory of \\ Energy Resource Utilization from Agriculture Residue, Ministry of Agriculture and Rural Affairs, Beijing 100125, China)
}

\begin{abstract}
This study evaluated eight different types of heat supply modes based on crop residues utilization in the rural area of Northern China, including straw densified solid fuel combustion, pyrolysis char combustion, biogas combustion, and pyrolysis gas combustion for single household heating; straw densified solid fuel combustion, baling straw combustion, biogas combustion, and pyrolysis gas combustion for centralized heating; centralized gas supply and centralized pyrolysis gas supply modes. Comprehensively evaluation was the cost of these different eight heat supply modes. The results showed that the cost of straw densified solid fuel combustion, pyrolysis char combustion for single household heating were $2346 \mathrm{RMB} /$ household and $2390 \mathrm{RMB} /$ household. With the heating scale of 200-500 households, the pipe network distance was $8 \mathrm{~m} /$ household, and the total annual heating cost was predicted at 2201-2992 RMB/household. Among them, the cost of straw baling combustion for centralized heating was the lowest, the cost of densified solid fuel, biogas, and pyrolysis for centralized heating was the second, and the cost of biogas and pyrolysis gas for centralized gas supply was the highest. For the increase in every $1 \mathrm{~m}$ of the pipeline distance, the investment cost will increase by about $645 \mathrm{RMB}$ for each household. This study provides a basis for the implementation of clean heat supply technologies in less-developed areas and guidance of village heat-supply subsidy policies.
\end{abstract}

Keywords: crop straw, biomass, clean heating, rural area, villages and towns, model, cost DOI: $10.25165 /$ j.ijabe.20201305.5600

Citation: Huo L L, Yao Z L, Jia J X, Zhao L X, Cong H B, Meng H B, et al. Evaluation of different clean heat supply modes based on crop straws in the rural area of Northern China. Int J Agric \& Biol Eng, 2020; 13(5): 209-217.

\section{Introduction}

As the largest grain producer of the world, China has plenty of biomass resources, the collectible straw resources are 674 million $\mathrm{t}$ in 2017, and the amount of straw utilization was 585 million $t$, there are still 89 million $t$ of straw wasted or burnt directly ${ }^{[1]}$, which resulted in serious energy waste and environmental pollution ${ }^{[1-3]}$. Straw has always been one of the main fuels for heating for rural residents ${ }^{[4]}$. The efficiency of straw direct combustion for decentralized heating was low, accompanied by high particulate matter $(\mathrm{PM})$ and nitrogen oxide $\left(\mathrm{NO}_{\mathrm{X}}\right)$ emissions, which caused seriously indoor and outdoor air contamination and is harmful to health. Another issue was the hidden dangers caused by the storage of the straw ${ }^{[5-7]}$. Straw can be used for clean heat supply with special combustion technology and equipment. As a result, straw can be used as a type of renewable energy. The proportion of renewable energy used in centralized heating in China was $1 \%$,

Received data: 2019-12-17 Accepted data: 2020-07-05

Biographies: Lili Huo, PhD, Senior Engineer, research interest: energy utilization of straw, Email: huolili666@126.com; Jixiu Jia, MS, research interest: agricultural waste utilization, Email: sdaujdjjx@163.com; Lixin Zhao, $\mathrm{PhD}$, Researcher, research interest: agricultural waste utilization, Email: zhaolixin5092@163.com; Hongbin Cong, PhD, Senior Engineer, research interest: energy utilization of straw, Email: conghongbin@163.com; Haibo Meng, PhD, Researcher, research interest: agricultural waste utilization, Email: newmhb7209@163.com; Yanwen Yuan, MS, research interest: waste utilization, Email: 32258472@qq.com

*Corresponding author: Zonglu Yao, PhD, Researcher, research interest: agricultural waste utilization. No. 12, Zhongguancun South Street, Haidian District, Beijing 100081, China. Tel: +86-10-82108783, Email: yaozonglu@163.com. which was far lower than that of the European Union $(19.3 \%)^{[8]}$, therefore, straw energy utilization in China has a great potential for development.

There was about $70 \%$ of the total land area requires for heat supply in China, which covers the Northern part of China (Figure 1) Energy used for heat supply is mainly produced by coal combustion. The annual consumption of coal used for heating was equal to 400 million tons of standard coal ${ }^{[9-11]}$. Coal decentralized combustion is mainly implemented in rural areas, which resulted in serious $\mathrm{PM}$, sulfur dioxide $\left(\mathrm{SO}_{2}\right)$ and $\mathrm{NO}_{\mathrm{X}}$ emissions. In recent years, to promote clean heating in winter in Northern China, the relevant government departments have taken measures including transition such as coal-to-electricity and coal-to-gas to alleviate air pollution. However, the cost of power grid transformation for adaption of such technologies in the rural area was high, and the supply of natural gas is insufficient. In the daily life of rural residents, heating energy consumption accounts for the largest proportion, which is about $59 \%$ of the total energy consumption $^{[12-14]}$. Therefore, how to convert the abundant straw of China into clean heat for rural areas is one of the effective ways to solve the above problems. The conversion was beneficial to the optimization of the energy structure of rural areas, improving the rural environment, improving the quality of living conditions of farmers, and promoting the green agriculture in China ${ }^{[15-18]}$.

The straw-based energy products for heat supply include straw densified solid fuel, baling straw, and pyrolysis charcoal, pyrolysis gas, biogas produced using straw as the feedstock (Figure 2).

Straw densified solid fuel is a kind of solid fuel, which be produced by compressing the straw into a specific shape through special equipment after crushing and drying and has increased 
density. It could be divided into compaction and granular fuels based on the product shape. The energy density was equal to that of the medium bituminous coal ${ }^{[19]}$. The fuel quality is sufficient to meet the requirements of the Chinese Agricultural Standard (NY/T 2909) and international standards (ISO 17225-6 and ISO $17225-7)^{[20-22]}$. Compared to the traditional bituminous coal, straw densified solid fuel has higher combustion efficiency, caused by easier ignition with a greatly shortened starting time of combustion. What's more, $\mathrm{CO}, \mathrm{NO}_{\mathrm{X}}, \mathrm{PM}$ emission and ash were low, and there was negligible $\mathrm{SO}_{2}$ emission ${ }^{[23]}$. Greenhouse gas emissions were zero for straw densified solid fuel combustion, which is beneficial to environmental improvement in rural areas ${ }^{[24]}$.

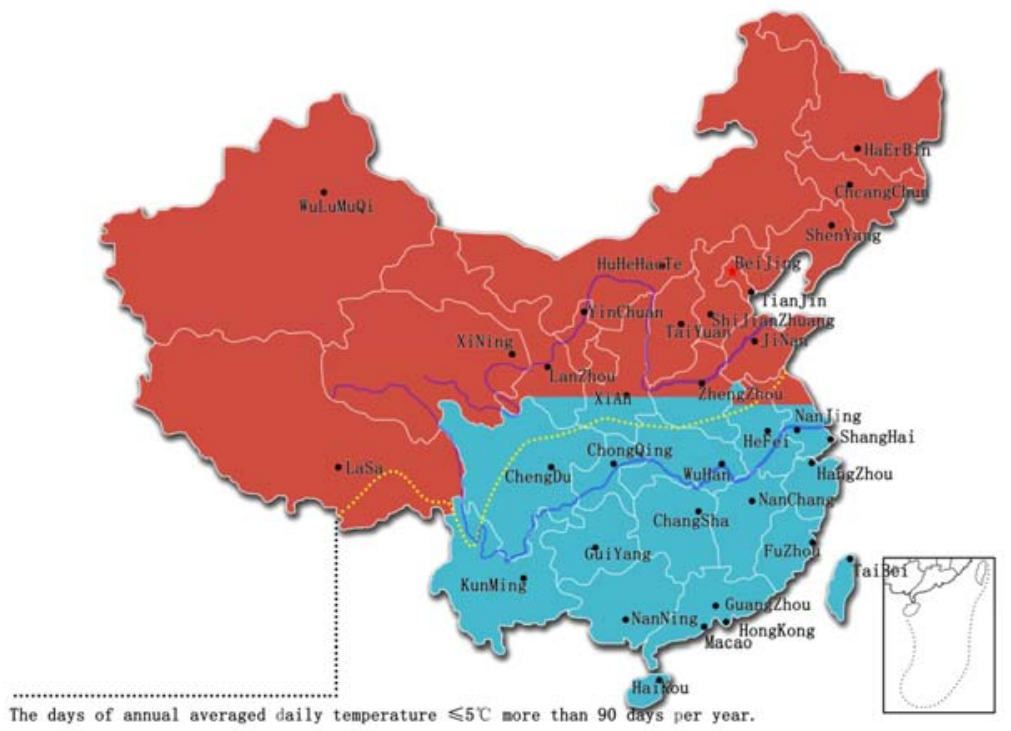

Note: 1 . Dividing line between the north and the south is divided by the annual average daily temperature stability $\leq 5^{\circ} \mathrm{C}$ for more than $90 \mathrm{~d}$; 2. North of the Qinghai-Tibet Plateau-Qinling-Huaihe line. In the diagram, the red area requires heat supply.

Figure 1 Schematic diagram of the area requires heat supply in Northern China

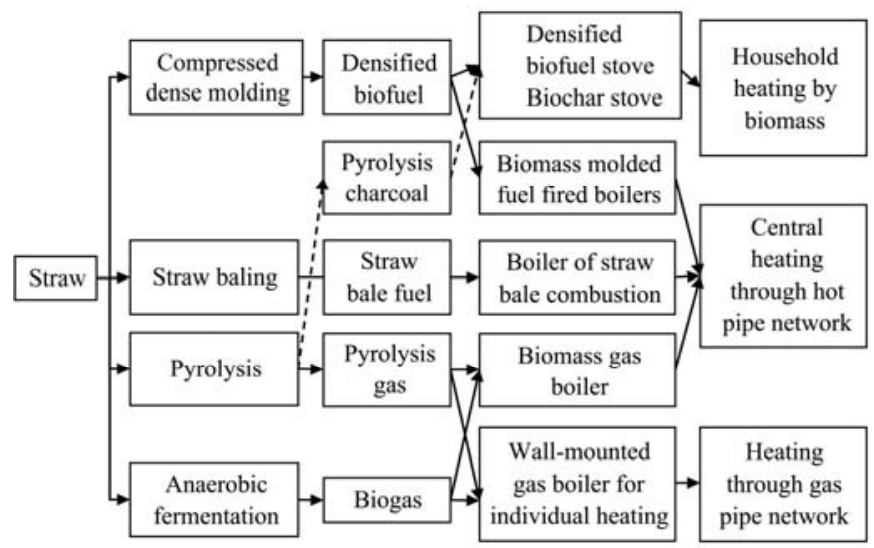

Figure 2 Typical mode of straw clean heating

Baling straw is a method to compress straw into round or square bundles by bundling equipment. At present, there was no standard for the regulation of the quality of baling straw. The emission of $\mathrm{NO}_{\mathrm{x}}$ and $\mathrm{PM}$ cannot meet the requirements of $\leq 150 \mathrm{mg} / \mathrm{m}^{3}$ and $\leq 50 \mathrm{mg} / \mathrm{m}^{3}$ in the application of single household heating with the existing technology, therefore, the study only considers the central heating mode. By actual testing, the moisture content and ash content of baling straw are normally 15\%-30\% and 10\%-30\%, respectively. The low calorific value and density of the baling straw were $10-14 \mathrm{MJ} / \mathrm{kg}$ and $300-$ $500 \mathrm{~kg} / \mathrm{m}^{3}$, respectively. Generally, baling straw is mainly combusted in a semi-gasification boiler and the product gas is transported to households for heating, and the thermal efficiency was high than $80 \%$. Compared to the straw densified solid fuel, baling straw requires no crush and molding. However, due to the lower density, the baling straw was occupied 2-4 times more space to store. Therefore, attention should be paid for storage, fire prevention and mildew prevention for baling straw. Moreover, the size of boilers and feeding equipment was relatively large at the same time, which increased the cost of primary investment.

Straw pyrolysis charcoal was a kind of solid produced by pyrolysis of the feedstock under absolute oxygen or anoxia. It can be used for dispersed heating. The calorific value of pyrolysis charcoal was higher than that of straw densified solid fuel, and the ash content was relatively higher ${ }^{[25,26]}$.

Pyrolysis gas is the gas produced by pyrolysis under the adiabatic or anoxic conditions, which contained a variety of components. The main combustion components gases were hydrogen, carbon monoxide and methane. The calorific value of pyrolysis gas was 3-5 times higher, and the impurities such as tar are low than the conventional straw gasification gas. There was no relevant quality standard for pyrolysis gas. For commercially useable pyrolysis gas, the low calorific value should be higher than $14 \mathrm{MJ} / \mathrm{m}^{3}$, tar and dust lower than $10 \mathrm{mg} / \mathrm{m}^{3}$, hydrogen sulfide lower than $20 \mathrm{mg} / \mathrm{m}^{3}$, ammonia lower than $50 \mathrm{mg} / \mathrm{m}^{3}$, carbon monoxide lower than $10 \%$, oxygen content lower than $2 \%$ according to Chinese National Standard (GB/T 13612) coal retort gas $^{[27]}$. The pyrolysis gas does not need desulfurization, but it requires tar and PM removal. The thermal efficiency of the pyrolysis gas boilers is higher than $90 \%$. Pyrolysis gas needs to be processed with deducting and denitrification facilities because it contains a small amount of tar and dust. Therefore, the primary investment, operation cost and maintenance cost were slightly higher than that of the biogas.

Straw biogas is a kind of combustible gas produced by the anaerobic fermentation of microorganisms under certain conditions of temperature, moisture, acidity and alkalinity. According to the Chinese National Standard (GB/T 51063), the calorific value needs to be more than $17 \mathrm{MJ} / \mathrm{m}^{3}$ and hydrogen sulfide was less than $20 \mathrm{mg} / \mathrm{m}^{3}$ (for domestic use) ${ }^{[31]}$. The main components of the biogas were $\mathrm{CH}_{4}$ and $\mathrm{CO}_{2}$. The thermal efficiency of biogas boilers was higher than $90 \%$. There was no PM emission during biogas burning. The post-processing requires dehydration and 
desulfurization facilities. After dehydration and desulfurization, biogas can be used for heating. Moreover, the content of S and N in biogas/biological natural gas was low, and the flue gas can meet the discharge standard. In addition, the investment, operation cost and maintenance cost were relatively low.

The typical clean heating mode for different straw energy products was displayed in Table 1 . The suitable heating modes were selected according to the characteristics of a single household, village, community and park. In order to achieve clean heating, the boiler for central heating with solid fuels such as straw densified solid fuel and baling straw needs to be equipped with tail gas treatment devices that mainly include dust removal and denitrification. Biogas, pyrolysis gas and other gas fuel do not need to be equipped with tail gas treatment devices, and their direct combustion can meet the requirements of relevant standards. The single household heating should meet the requirements of the Chinese Energy Industrial Standard (NB/T $34006)^{[29]}$, flue gas emission $\mathrm{PM} \leq 50 \mathrm{mg} / \mathrm{m}^{3}, \mathrm{SO}_{2} \leq 30 \mathrm{mg} / \mathrm{m}^{3}$, $\mathrm{NO} \leq 150 \mathrm{mg} / \mathrm{m}^{3}, \mathrm{CO} \leq 0.2 \%$, Randleman blackness $\leq 1$. Special boilers are used for centralized heating, and the flue gas emissions should meet the requirements of the Chinese National Standard (GB 13271) $)^{[30]}$.

Table 1 Details of typical clean heating mode for different straw energy products

\begin{tabular}{|c|c|c|}
\hline Product & Heat supply modes & Main features and applicability \\
\hline \multirow{2}{*}{$\begin{array}{l}\text { Straw } \\
\text { densified } \\
\text { solid } \\
\text { fuel }\end{array}$} & $\begin{array}{l}\text { Single household heating mode of "straw } \\
\text { densified solid fuel+small special stove } \\
\text { heating" }\left(\mathrm{S}_{\mathrm{pel}}\right)\end{array}$ & $\begin{array}{l}\text { The thermal efficiency can be higher than } 70 \% \text { using a special furnace }{ }^{[29,31]} \text {, which is suitable for small } \\
\text { villages and towns. }\end{array}$ \\
\hline & $\begin{array}{l}\text { Centralized heating mode of "straw } \\
\text { densified solid fuel+special boiler+heating } \\
\text { network" }\left(\mathrm{C}_{\mathrm{pel}}\right)\end{array}$ & $\begin{array}{l}\text { When a special boiler was used for clean combustion, the heat efficiency of the boiler can be higher than } \\
80 \%{ }^{[26]} \text {, which is slightly higher than that of traditional coal boilers }{ }^{[32]} \text {. }\end{array}$ \\
\hline $\begin{array}{c}\text { Baling } \\
\text { straw }\end{array}$ & $\begin{array}{l}\text { Centralized heating mode of "baling } \\
\text { straw+semi-gasification bundling+heating } \\
\text { network" }\left(\mathrm{C}_{\text {bund }}\right)\end{array}$ & $\begin{array}{l}\text { Semi-gasification boiler can be used combined with the central heating network. Thermal efficiency of the } \\
\text { boiler was higher than } 80 \% \text {. }\end{array}$ \\
\hline $\begin{array}{l}\text { Pyrolysis } \\
\text { charcoal }\end{array}$ & $\begin{array}{l}\text { Single household heating model of } \\
\text { "pyrolysis charcoal+small-sized special } \\
\text { stove heating" }\left(\mathrm{S}_{\text {char }}\right)\end{array}$ & $\begin{array}{l}\text { Pyrolytic charcoal stove was used, and the thermal efficiency was higher than } 70 \% \text {, which is the same as the } \\
\text { single household heating mode of "straw densified solid fuel and suitable for a single household or scattered } \\
\text { heating in villages and towns. }\end{array}$ \\
\hline \multirow[b]{2}{*}{$\begin{array}{l}\text { Pyrolysis } \\
\text { gas }\end{array}$} & $\begin{array}{l}\text { Centralized heating mode of "heat and } \\
\text { chercoal combined production using } \\
\text { straw }+ \text { heating network+carbon fertilizer for } \\
\text { farmland" }\left(\mathrm{C}_{\text {pyroheat }}\right)\end{array}$ & $\begin{array}{l}\text { High-temperature pyrolysis gas was directly used for combustion without the separation of tar, then } \\
\text { transported to users through the heating network; Pyrolysis charcoal can be used as carbon-based fertilizer } \\
\text { to improve the quality of agricultural products and increase soil carbon. }\end{array}$ \\
\hline & $\begin{array}{l}\text { Centralized gas supply mode of "gas and } \\
\text { carbon co-production using straw }+ \text { gas } \\
\text { network+wall-mounted furnace heating" } \\
\left(\mathrm{C}_{\text {pyrogas }}\right)\end{array}$ & $\begin{array}{l}\text { The high-temperature pyrolysis gas was separated and purified by condensation. It can be supplied to } \\
\text { households, and the heating time can be controlled autonomously. This mode can share the network with } \\
\text { cooking and hot water supply. Pyrolysis charcoal can be used to selectively produce pyrolytic charcoal or } \\
\text { carbon-based fertilizer products according to market demand, which can meet the needs of clean heating or } \\
\text { agricultural production. This mode has the advantages of clean energy conversion, diverse hot carbon } \\
\text { products, high-grade energy, and low } \mathrm{NO}_{\mathrm{X}} \text { and PM emission. }\end{array}$ \\
\hline \multirow{2}{*}{ Biogas } & $\begin{array}{l}\text { Centralized heating mode of "straw } \\
\text { biogas+heating network+biogas slurry } \\
\text { returning to the field" }\left(\mathrm{C}_{\text {bioheat }}\right)\end{array}$ & $\begin{array}{l}\text { The biogas produced by anaerobic fermentation was burned in special methane boiler and heating was } \\
\text { provided through the heating network. Biogas slurry and residue can be used as fertilizer. This mode is } \\
\text { suitable for huge heating needs combined agricultural with sophisticated infrastructures. Biogas can } \\
\text { effectively replace coal, optimize the structure of agricultural energy consumption. }\end{array}$ \\
\hline & $\begin{array}{l}\text { Centralized gas supply mode of "straw } \\
\text { biogas+heating network+wall-mounted } \\
\text { furnace heating" }\left(\mathrm{C}_{\text {biogas }}\right)\end{array}$ & $\begin{array}{l}\text { The biogas produced by anaerobic fermentation was burned in special methane boiler and heating was } \\
\text { provided through the heating network, the heating time could be controlled autonomously. This mode can } \\
\text { share the network with cooking and hot water supply. Biogas slurry and biogas residue can be used as } \\
\text { solid and liquid organic fertilizer according to market demand, and meet the demand of facility agriculture. }\end{array}$ \\
\hline
\end{tabular}

\section{Materials and methods}

\subsection{Evaluation methods}

The research was based on five kinds of products derived from straw, including straw densified solid fuel, baling straw, pyrolysis charcoal, pyrolysis gas and biogas. The heating area of each household in rural areas was $100 \mathrm{~m}^{2}$. For centralized heating, the research selected 50-500 households. The authors compared the cost of these eight different heat supply modes, which are intended to provide theoretical reference for single household, village, community and park heating in Northern China.

The heating load time was calculated according to Equations $(1)-(3)^{[5]}$.

$$
\begin{gathered}
t_{h}=t_{d}\left(t-\beta \frac{t-5}{1+b}\right) \\
\beta=\frac{\theta_{i n}-\theta_{o, a v}}{\theta_{i n}+\theta_{o, c}} \\
b=\frac{5-\theta_{o, a v}}{\theta_{o, a v}+\theta_{o, c}}
\end{gathered}
$$

where, $t_{h}$ is the conversion of the heating period into design heat load time, $\mathrm{h} ; t_{d}$ is the daily time for $24 \mathrm{~h}, \mathrm{~h} ; t$ is the heating time during the heating period, $\mathrm{d} ; \beta$ factor; $b$ is correction factor; $\theta_{i n}$ is the designed temperature of the heating room, ${ }^{\circ} \mathrm{C} ; \theta_{o, a v}$ is the average outdoor temperature during the heating season, ${ }^{\circ} \mathrm{C} ; \theta_{o, c}$ is the outdoor calculated temperature for heating, ${ }^{\circ} \mathrm{C}$. A case study of winter climate in Hebei, China, $t=120 \mathrm{~d}, \theta_{i n}=18^{\circ} \mathrm{C}, \theta_{o, a v}=-0.7^{\circ} \mathrm{C}$, $\theta_{o, c}=-7.6^{\circ} \mathrm{C}$. The designed heat load time during heating time lasted for the $1776 \mathrm{~h}$, which means the heating time was $14.8 \mathrm{~h} / \mathrm{d}$.

The annual heat load demand was calculated according to Equation (4).

$$
G=q \cdot t_{h}: S \times 3.6 \times 10^{-6}
$$

where, $G$ is the annual heat load demand, GJ; $q$ is the heating index, $\mathrm{W} / \mathrm{m}^{2} ; S$ is the total heating area, $\mathrm{m}^{2}$. According to the Design Code for Urban Thermal Network (CJJ34) ${ }^{[33]}$, The range of heating heat index $q$ is $40-45 \mathrm{~W} / \mathrm{m}^{2}$. According to the literature ${ }^{[9]}$, the proportion of new urban buildings in the northern region to implement the mandatory energy-saving standards is nearly $100 \%$. At present, the proportion of energy-saving buildings is more than $50 \%$, and only $20 \%$ of rural heating buildings have taken certain 
energy-saving measures. Based on the low proportion of rural energy-saving, here $45 \mathrm{~W} / \mathrm{m}^{2}$ is used.

$$
M=\frac{q \cdot t_{h}}{Q_{i}+\delta} \times 3.6
$$

where, $M$ is the fuel consumption, $\mathrm{kg}$ or $\mathrm{m}^{3} ; q$ is the heating index, $\mathrm{W} / \mathrm{m}^{2} ; Q_{i}$ is the low calorific value of the fuel, $\mathrm{kJ} / \mathrm{kg}$ or $\mathrm{kJ} / \mathrm{m}^{3} ; \delta$ is the thermal efficiency of the boiler (furnace), $\%$.

\subsection{Data sources}

Detailed information for heating in winter was shown in Table

2. In this table, the annual heat demand was calculated according to the heating area and the heat demand per unit. The thermal efficiency limit of the boiler referred to the standard GB/T51063 ${ }^{[29]}$; The rated power was calculated according to the different heating modes, which include central heating and single household heating.

Table 2 Detail information for heating in winter

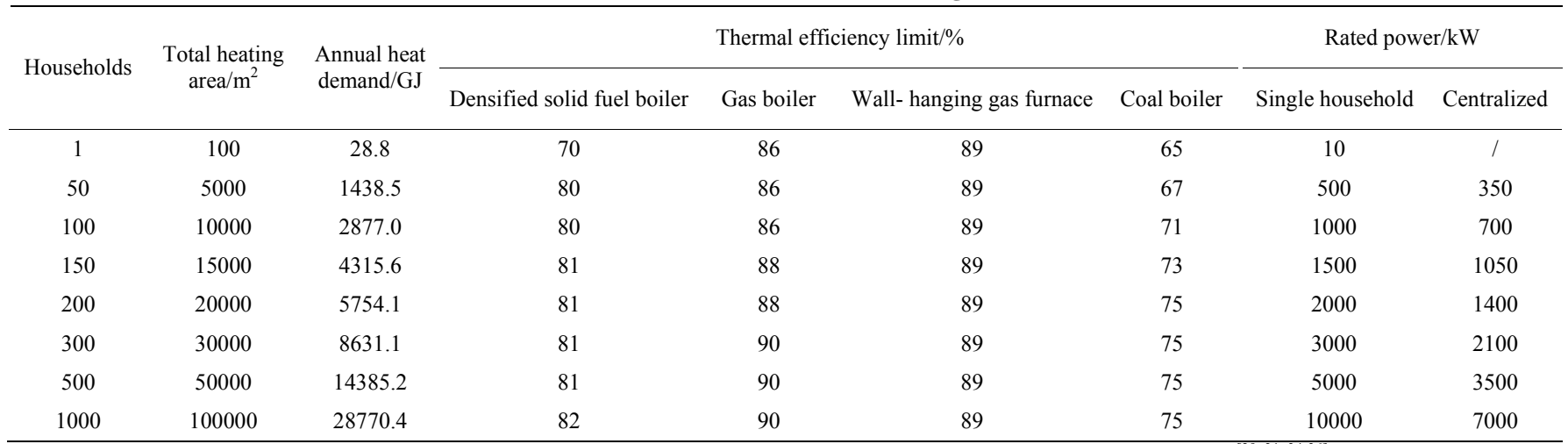

Note: 1 . The rated power of a single household stove is the cumulative value; 2 . Thermal efficiency limit has been shown previously ${ }^{[29,31,34-36]} ; 3$. Thermal efficiency of straw bundle boilers and densified solid fuel referred to relevant standards of straw densified solid fuel.

The heating costs include costs for fuel, operating power and labor, initial investment depreciation, management and profits. The operating power and labor cost were calculated according to the power consumption of different heating boilers and staff salaries. The primary investment cost included the cost of the heating boiler, purification and degusting systems, heating network, heat dissipation system, and heat dissipation system. The depreciation period was 15 years. The cost of different fuels shown in Table 3 and the data of fuel prices are obtained from the field investigation of three counties in Hebei Province. The price of the heating network and heat dissipation system was $15 \mathrm{RMB} / \mathrm{m}^{2}$ according to the investigation results. The household stoves cost $3200 \mathrm{RMB} /$ household. Management cost was $3 \%$ and the operation management cost was $10 \%$ of operation power and labor cost. The profit of the centralized heating party was $10 \%$ of the total cost, and that of the single household heating was excluded. The cost of a centralized heating network was $400 \mathrm{RMB} / \mathrm{m}$ and the distance of network was $400 \mathrm{~m}$ for every 50 households. The cost of an external network of centralized gas supply network was $400 \mathrm{RMB} / \mathrm{m}$. The transporting distance of the external network of centralized heat supply and gas supply network was $480 \mathrm{~m}$ for 60 households ( $8 \mathrm{~m} /$ household), and the analytical distance was in the range of $8-40 \mathrm{~m} /$ households.

Table 3 Calorific values and unit prices of different fuels

\begin{tabular}{lclc}
\hline \multicolumn{1}{c}{ Fuel type } & LHV & Units & Unit price/RMB \\
\hline Straw densified solid fuel & 12.6 & $\mathrm{MJ} / \mathrm{kg}$ & 600 \\
Baling straw & 10.0 & $\mathrm{MJ} / \mathrm{kg}$ & 400 \\
Biogas & 17.0 & $\mathrm{MJ} / \mathrm{m}^{3}$ & 1 \\
Pyrolysis gas & 18.0 & $\mathrm{MJ} / \mathrm{m}^{3}$ & 1 \\
Pyrolysis charcoal & 21.0 & $\mathrm{MJ} / \mathrm{kg}$ & 1000 \\
Fire coal & 20.9 & $\mathrm{MJ} / \mathrm{kg}$ & 1000
\end{tabular}

Note: 1. Calorific values in table 3 are all low calorific values; 2 . Fuel price is based on the field survey of northern villages and towns in 2018, which is the unit price of fuel in three counties of Hebei Province; 3. Calorific value of straw bale fuel is the low calorific value of the received basis, compared with briquette fuel, straw bales are slightly lower due to different moisture content.

\section{Results}

\subsection{Cost analysis of different heat supply modes}

As shown in Figure 3, the cost of centralized heating decreased as the number of heating households increased. When the number of heating households increased from 50 to 200, the cost decreased significantly. Compared with 50 households, the heating cost of baling straw of 200 households can be reduced by $13 \%$, from 2632.0 RMB/household to $2293.7 \mathrm{RMB} /$ household. The heating cost of straw densified solid fuel can be reduced by $11 \%$, from 2893.0 RMB/household to $2566.2 \mathrm{RMB} /$ household. Under the modes of biogas and pyrolysis gas for centralized heating, the heating cost can be reduced by about $9 \%$. Under the modes of biogas and pyrolysis gas decreased the heating cost can be reduced by about $6 \%$.

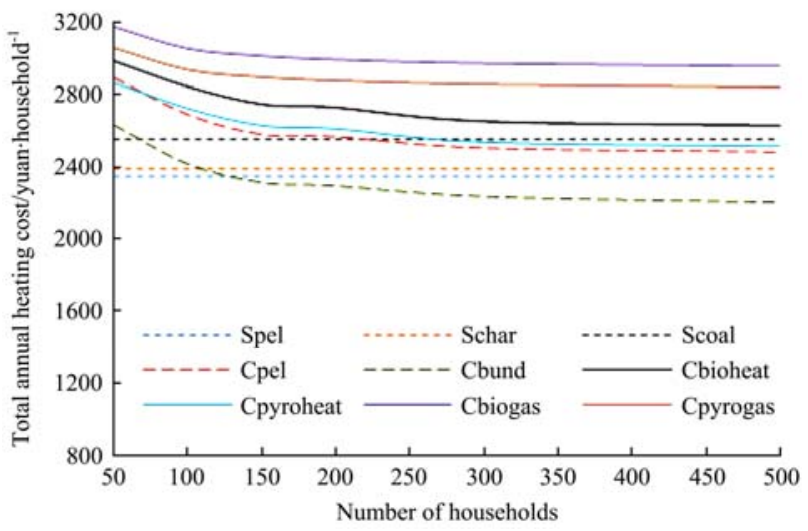

Figure 3 Total annual heating cost

The heating cost of households larger than 200 reduced slowly. Based on the heating cost, for a single household, it is recommended to adopt the straw densified solid fuel/carbon for heating.

As shown in Figure 4a, for straw baling, the cost of centralized heating was equal to that of the single household heating when the number of households was 50 . For the other heat supply modes, the cost of single household heating was lower than that of the 
centralized heating. Among them, the cost of the single household heating with straw densified solid fuel was the lowest. The total heating cost of single household heating with straw densified solid fuel and pyrolysis carbon was $2346 \mathrm{RMB} /$ household and $2390 \mathrm{RMB} /$ household, respectively. For these two heat supply modes, the cost was reduced by about $8.0 \%$ and $6.3 \%$ compared with traditional coal combustion, respectively. The costs of baling straw combustion, straw densified solid fuel combustion, biogas combustion, pyrolysis gas combustion for heating, biogas supply, pyrolysis gas supply were 2632 RMB/household, 2893 RMB/household, 2985 RMB/household, $2865 \mathrm{RMB} /$ household, $3174 \mathrm{RMB} /$ household and 3057 $\mathrm{RMB} /$ household, respectively (the distance of network was $8 \mathrm{~m} /$ household).

As displayed in Figure 4b, the cost of centralized heating was equal to that of single household heating when the number of households was 200. The cost of centralized gas supply was higher than other heat supply modes, followed by gas centralized heating and straw densified solid fuel centralized heating. The cost of baling straw centralized heating was the lowest. The total heating cost of centralized heating with straw baling, straw densified solid fuel, biogas, pyrolysis gas, biogas supply, and pyrolysis gas supply were $2294 \mathrm{RMB} /$ household, 2566 RMB/household, 2728 RMB/household, 2611 RMB/household, $2992 \mathrm{RMB} /$ household, and $2876 \mathrm{RMB} /$ household (the distance between households was $8 \mathrm{~m}$ ).

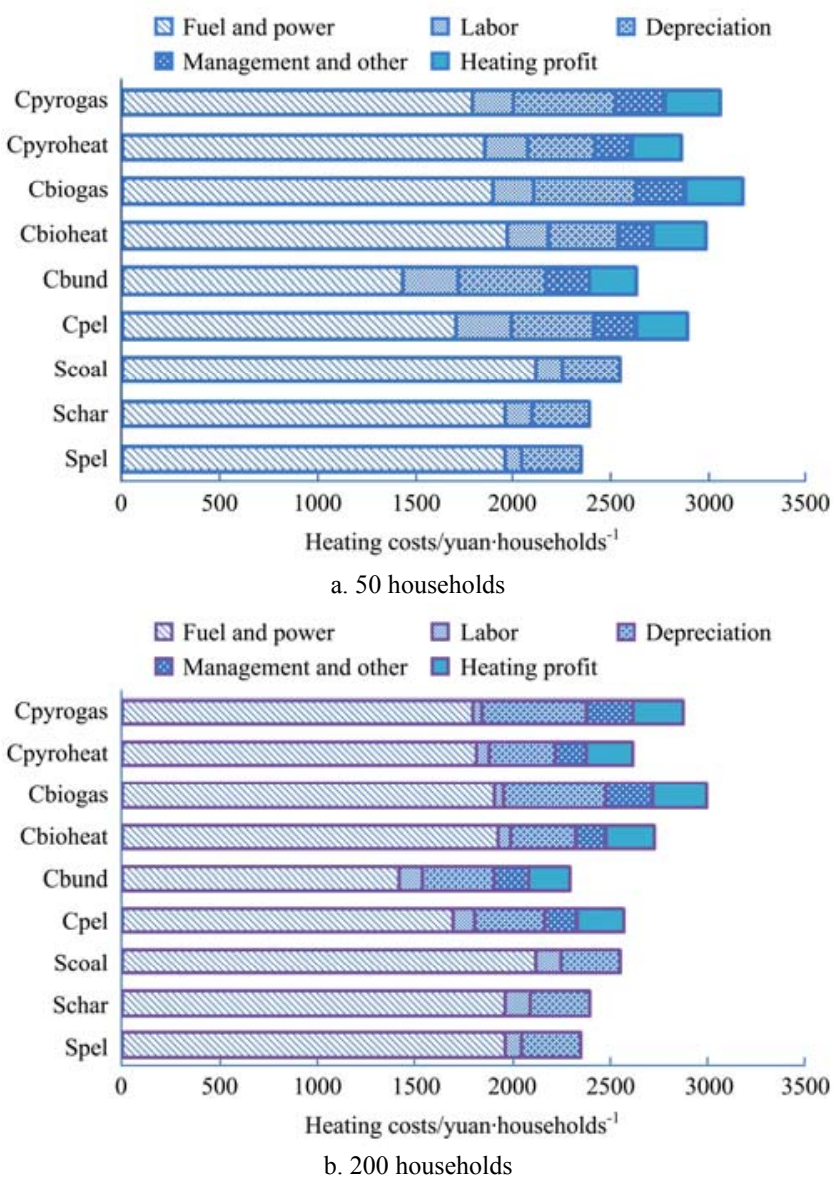

Figure 4 Costs of different heat supply modes

The fuel cost of single household heating was the highest, accounting for about $83 \%$ of the total heating cost. For centralized heating, the fuel cost was unchanged with the number of households increased, but the fuel cost proportion in the total cast increased. Fuel cost of 200 households accounts for
$61 \%-70 \%$ of the total heating cost, and fuel cost accounting for $55 \%-65 \%$ of the total cost when the number of households was 50 . The fuel cost of 200 households increased by 5\%-6\% compared with 50 households. The depreciation cost of single household heating accounts for $13 \%$ of the total heating cost. With the increase of the heating scale, the depreciation cost of centralized heating reduced, and the depreciation cost of gas supply mode was higher than that of other heating modes, accounting for about $22 \%$ of the total cost. The depreciation cost of centralized heating for 200 households and 50 households accounted for $14 \%-16 \%$ and $15 \%-19 \%$, respectively.

\subsection{Cost of the primary investment cost}

Primary investment of the centralized heat supply modes included the costs of the boiler, dust removal and purification system, heating network, and radiator. For the centralized gas supply, primary investment included a centralized gas supply network and gas heating (wall-mounted) furnace. As shown in Figure 5, the primary investment of baling straw, straw densified solid fuel, biogas and pyrolysis gas centralized heating mode decreased when the number of households increased.

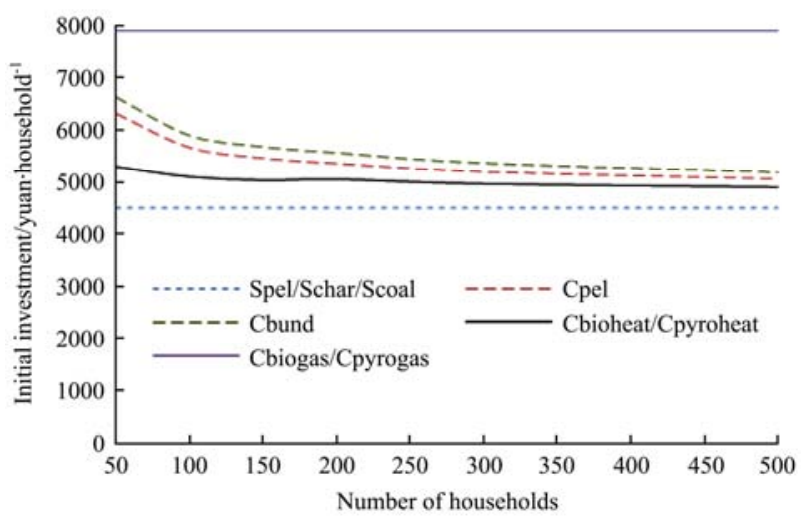

Figure 5 Initial investment cost of different heat supply modes

Primary investment reduced quickly the number of heating households increased from 50 to 200 . When the number of heating households was 200 , the primary investment of centralized heating with baling straw and straw densified solid fuel reduced $15 \%$ compared with that of 50 households. The primary investment of centralized heating with biogas and pyrolysis gas for 200 households was reduced by $5 \%$. Primary investment reduced slowly as the number of households more than 200. The primary investment of centralized gas supply with biogas and pyrolysis did not change with household number increased, and the maximum primary investment cost was $7900 \mathrm{RMB} /$ household.

The distance of the network for the above researches was 8 $\mathrm{m} /$ household, and the network distance significantly affects the investment cost, which in turn affects the total heating cost. Primary investment and the total heating cost significantly increased as the distance of the network increased. As shown in Figure $6 \mathrm{a}$. When the network distance was between $8 \mathrm{~m}$ to $40 \mathrm{~m}$, the total annual heating cost increased $43 \mathrm{RMB} /$ household for the increase in distance by $1 \mathrm{~m}$. Taking 200 households as an example, when the distance of network was $20 \mathrm{~m}$, the total investment of the heating cost increased about $17 \%$ to $22 \%$, and the primary investment accounts for $21 \%$ to $24 \%$ of the total heating cost. The total cost for the centralized heating with baling straw, straw densified solid fuel, biogas, pyrolysis gas was 2804 RMB/household, 3077 RMB/household, 3238 RMB/household and $3121 \mathrm{RMB} /$ household, respectively. The total costs of biogas centralized supply and pyrolysis gas supply heating were 
$3503 \mathrm{RMB} /$ household and $3386 \mathrm{RMB} /$ household, as shown in Figure $6 \mathrm{~b}$. When the average distance of the network was $30 \mathrm{~m}$, the average primary investment increased $32 \%-41 \%$, accounting for $25 \%-30 \%$ of the total heating cost. When the average distance of the network was $40 \mathrm{~m}$, the average primary investment increased $46 \%-60 \%$, accounting for $29 \%-32 \%$ of the total heating cost. Considering the heating cost, it was not appropriate to choose a centralized heating mode when the average distance of the network was more than $27 \mathrm{~m}$, instead, it was better to adopt the single household heating.

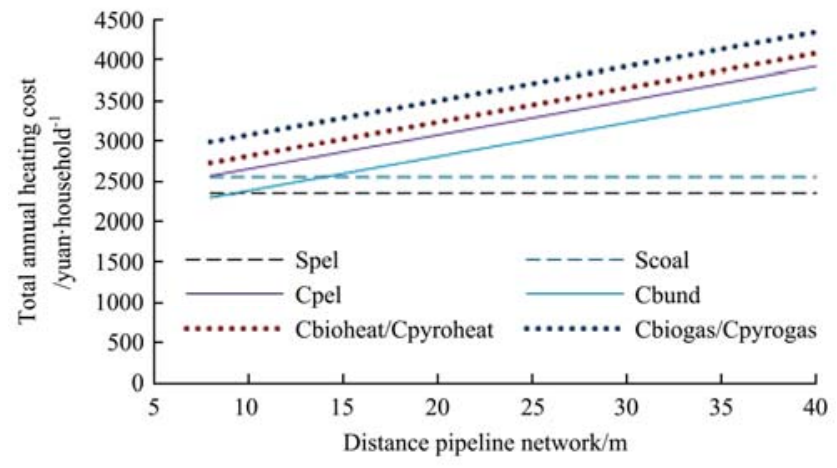

a. Total annual heating cost

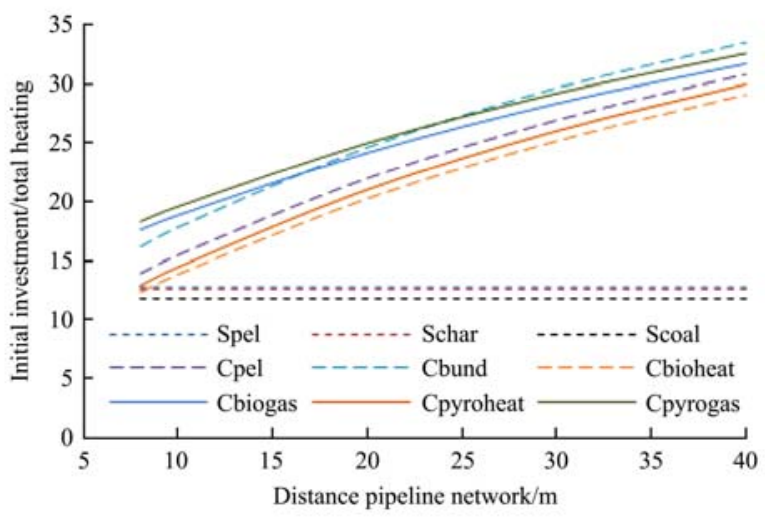

b. Initial investment/Total

Figure 6 Influence of pipe network distance on heating cost

\subsection{Annual cost of the heat supply operation}

The annual costs for the heat operation of centralized heating decreased with the number of heating households increased. When the number of households between 50 and 200, annual heating operation cost reduced quickly. The annual heating operation cost reduced slowly as the number of households more than 200, as shown in Figure 7.

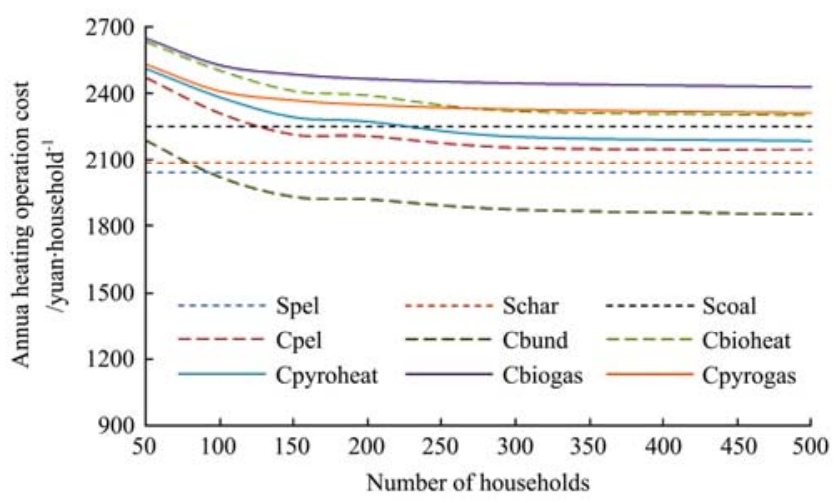

Figure 7 Influence of the number of heating households on the annual cost of heat supply

As shown in Figure 8, the average distance of network was $8 \mathrm{~m}$, taking the size of 50 households as an example, the annual heating operation cost of single household heating with straw densified solid fuel and pyrolysis carbon mode were $2046 \mathrm{RMB} /$ household and $2090 \mathrm{RMB} /$ household, respectively, which were $9.1 \%$ and $7.2 \%$ lower that of traditional coal combustion. The annual heating operation cost of the centralized heating with baling straw, straw densified solid fuel, biogas, and pyrolysis gas were 2189 RMB/household, $2471 \mathrm{RMB} /$ household, $2632 \mathrm{RMB} /$ household, and $2512 \mathrm{RMB} /$ household, respectively. For biogas and pyrolysis gas centralized supply, the annual heating operation costs were $2647 \mathrm{RMB} /$ household and $2531 \mathrm{RMB} /$ household, respectively. Taking 200 households as an example, the annual heating operation costs of centralized heating with baling straw, straw densified solid fuel, biogas and pyrolysis gas were $1923 \mathrm{RMB}$ /household, 2209 RMB/household, $2391 \mathrm{RMB} /$ household, and $2274 \mathrm{RMB} /$ household, respectively. For biogas and pyrolysis gas centralized supply heating, the annual heating operation costs were 2466 $\mathrm{RMB} /$ household and $2349 \mathrm{RMB} /$ household. The annual heating operation cost increased with the increase in the network distance, which is mainly because of the increase in maintenance and operation costs.

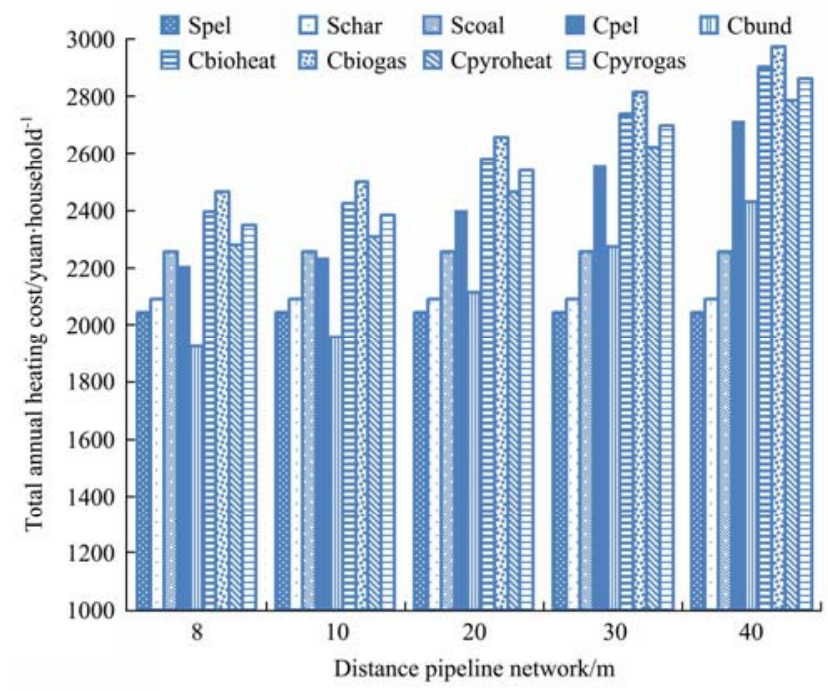

Figure 8 Influence of pipe network distance on the annual heating operation cost

\subsection{Further discussion}

At present, the distribution network, natural gas network and heating network in the northern rural area has not been fully developed. The capacity of the rural household distribution network was still low, the average capacity of the household power grid line was 2-3 kW, but it requires $9-10 \mathrm{~kW}$ for electric heating in winter. Although some parts of the rural area have reserved gas supply ports, it is difficult to implement gas heating. At the same time, the cost of the natural gas heating was high ${ }^{[37]}$, and the seasonal peak shaving capacity of supply was insufficient, which was difficult to meet the demand. There was still a certain gap between the application of "coal to electricity" and "coal to gas" in vast rural areas. The northern rural still need to identify the feasible clean heating route based on local resource endowments, habits, economic capabilities and infrastructure ${ }^{[38]}$. The application of straw clean heating technology can supplement the energy demand for clean heat supply ${ }^{[39]}$.

The straw clean heating technology has the advantages of abundant straw resources, negligible $\mathrm{SO}_{2}$ emissions, low $\mathrm{CO}$, $\mathrm{NO}$, particulate matter and solid ash emissions. It can replace coal, natural gas and other primary energy sources, and effectively improve the living and atmospheric environment in rural areas. 
The existing research introduced the straw clean heating modes, but all of them are aimed at the analysis of a single technical mode, therefore a lack of systematic analysis of different modes regarding technical feasibility and application suitability. The energy provided by the popularization and application of straw clean heating technology equal to 1.1-1.3 t standard coal for every household, which can reduce the emissions of $\mathrm{CO}_{2}, \mathrm{SO}_{2}, \mathrm{NO}_{\mathrm{x}}$ and PM by $2884-3625 \mathrm{~kg}, 9.3-11.8 \mathrm{~kg}, 8.1-10.2 \mathrm{~kg}$, and 740-940 kg, respectively.

3.4.1 Suitability of application for different modes

The single-household heating with straw densified solid fuel and pyrolytic carbon has advantages including convenient storage and transportation, high combustion efficiency, low energy consumption and low $\mathrm{NO}_{\mathrm{x}}$ and $\mathrm{PM}$ emissions. However, the disadvantage of the single household heating was the emission control, for which the total cumulative pollutant emission was higher than that of centralized heating or gas supply mode. Therefore, single-household heating was suitable for small-scale, villages, towns, and small agricultural parks.

The PM, $\mathrm{NO}_{\mathrm{x}}$, and $\mathrm{SO}_{2}$ emissions of the centralized heating mode with straw densified solid fuel or baling straw can meet the requirements of environmental protection as there is the gas purification system. The operating cost and energy consumption of these modes were low. Therefore, these modes were suitable for villages and communities which has a general level of economic development, moderate scale, concentrated population, as well as large and medium-sized facilities agricultural parks. It is necessary to pay attention to the storage safety of the fuel, and fire protection, moisture-proof and rain-proof, especially the baling straws which requires large space for storage.

The centralized heating mode with biogas and pyrolysis gas was suitable for villages, communities and parks with a general level of economic development, moderate scale, and concentrated population. The cost of biogas or pyrolysis gas centralized supply mode was high based on the results from the traditional calculation. However, the heating time of these modes can be controlled, which can effectively reduce heating operation costs. These modes were suitable for communities and parks with a higher level of economic development, better infrastructure, and a larger population, which can also solve the fuel demand for cooking and hot water. These modes could reduce investment and operation costs. But it is necessary to reduce the distance of the network according to local conditions and control the investment cost.

\subsubsection{Cost of the centralized heating system}

Since the distance of the network was long in the village as the building in rural areas was scattered, therefore the cost of these clean heating mode based on straw was high ${ }^{[23]}$. This caused unacceptability and difficulty of marketization. The clean heating based on straw required financial support from the government, for example, corresponding subsidy policy for rural clean heating to ensure the implementation and sustainable development of rural clean heating projects ${ }^{[40]}$.

As shown in Table 4, the cost of centralized heating with coal was $2500 \mathrm{RMB} /$ household $\left(25 \mathrm{RMB} / \mathrm{m}^{2}\right)$. The distance of the network should be within $15 \mathrm{~m}, 9 \mathrm{~m}, 7 \mathrm{~m}$, and $7 \mathrm{~m}$ for baling straw, straw densified solid fuel, biogas and pyrolysis gas centralized heating mode if the users do not want to pay much more than coal. The biogas and pyrolysis gas centralized supply mode do not suit for rural areas because these modes cost too high. If the heating cost reaches developed cities, such as Beijing, the cost can reach $3000 \mathrm{RMB} /$ household $\left(30 \mathrm{RMB} / \mathrm{m}^{2}\right.$ ), the distance of the network of centralized heating with baling straw, straw densified solid fuel, biogas and pyrolysis gas should be less than $27 \mathrm{~m}, 21 \mathrm{~m}, 18 \mathrm{~m}$, and $18 \mathrm{~m}$, respectively. The distance of the network for biogas and pyrolysis gas centralized supply heating should be less than $12 \mathrm{~m}$.

The cost of the user included annual heating operation cost, as well as one-time investment depreciation cost for the network and radiator (wall-hanging stove), and does include one-time investment depreciation fees for dust removal, purification systems and the gas supply network. The cost of centralized heating reduced as the number of households increased. Centralized heating was not suitable for the number of households less than 200 based on the authors' research. As shown in Table 5, a comparison of several types of central heating modes with 500 households and 200 households, the cost of gas heating mode did not change significantly, and the cost of other heating modes can be lower by about 3\%. The heating cost ranged from 1856 to $2466 \mathrm{RMB} /$ household as the number of households was between 200 and 500 and the average distance of the network was $8 \mathrm{~m}$. The cost of the centralized heating with baling straw was the lowest, while the cost of biogas and pyrolysis gas centralized heating modes were the highest.

The cost of the boiler, dust removal and purification system for the centralized heating or gas supply network was 3000$4050 \mathrm{RMB} /$ household, and the depreciation cost accounts for $7 \%-12 \%$ of the total heating cost. The investment increased $645 \mathrm{RMB} /$ household as the distance increased by one meter. The results suggested that in view of the above cost analysis for heat supply in Northern China, the corresponding subsidy policies should be established for boilers, dust removal and purification systems, and the centralized heating or gas supply network.

3.4.3 Implications of the current research

The thermal insulation performance of the houses in the rural areas was poor, therefore the existing building design and the implementation still cannot reach the relevant energy-saving standard, which in turn led to severe consumption of the heat. The rural areas should pay attention to the energy-saving transformation of the building, the construction of the passive house, the enhancement of the automatic control capacity of the heating system, to improve the heat efficiency of the heat supply system. In this study, the heat index of heating is calculated using the low value. According to the difference of heat preservation and energy saving of the house, the actual total heating load required in winter varied significantly ${ }^{[41]}$.

Currently, the price of straw gas products was low. The prices of biogas and pyrolysis gas will increase in the future with the increase in the cost of the straw-based energy products, which will directly affect the cost of gas supply. The profit of the heater under the centralized heating mode was low, which was calculated by $10 \%$ of the total cost. There are still many uncertainties in the actual heating process that will affect the heating cost and efficiencies, such as whether the straw energy products can be sustained and stable supply, the rise of labor cost, fuel storage and management cost.

\section{Conclusions}

In this study, by studying the eight kinds of heat supply modes based on agriculture residue utilization, the results provide the basis for selecting schemes for straw clean heating applications in rural areas in Northern China, such as single households, natural villages, communities and parks.

In small towns with less than 200 households and scattered 
villages and towns with pipeline network distance more than $27 \mathrm{~m} /$ household, the heating cost advantages of the single household heating mode of straw densified solid fuel and pyrolysis carbon are obvious. So it is unsuitable to choose a centralized heating mode. The annual total heating cost of a single household heating mode of straw densified solid fuel and pyrolysis carbon is $2346 \mathrm{RMB} /$ household and $2390 \mathrm{RMB} /$ household, respectively.

Amongst the centralized heating modes, the baling straw centralized heating mode has the lowest cost and is suitable for villages or parks with poor economic conditions. The centralized heating mode of straw densified solid fuel, biogas and pyrolysis gas takes second place in cost, which is suitable for popularization in villages or parks with general economic conditions. The centralized gas supply mode of biogas and pyrolysis gas has the highest cost and is suitable for popularization in villages or parks with better economic conditions. The centralized heating scale is 200-500 households; the distance of the pipeline network is $8 \mathrm{~m} /$ household. The total annual heating cost is 2201$2992 \mathrm{RMB} /$ household. The investment cost increases by about $645 \mathrm{RMB} /$ household for each $1 \mathrm{~m}$ increase in pipeline network distance.

The economic cost of eight kinds of straw clean heating modes is reasonable, therefore, these modes and can be applied in villages and towns. The average annual replacement of standard coal can reach 1.1-1.3 t, and the average annual emission reduction of $\mathrm{CO}_{2}$ is $2884-3625 \mathrm{~kg}, \mathrm{SO}_{2}$ is $9.3-11.8 \mathrm{~kg}$, NOx is $8.1-10.2 \mathrm{~kg}$ and particulate matter is $740-940 \mathrm{~kg}$, which has good environmental benefits.

It is worth noticing that so far the infrastructure of clean heating in villages and towns is still weak. It is suggested that the investment subsidy or incentive policies should be established for straw clean heating facilities and equipment, heating, or gas supply network. Moreover, the application and popularization of straw clean heating technology should be strengthened to promote the rural energy revolution.

\section{Acknowledgements}

The authors acknowledge that this work was financially supported by the Agricultural Science and Technology Innovation Program (CAAS-ASTIP), China Agriculture Research System (CARS-02), which enables us to complete field surveys and data analysis.

\section{[References]}

[1] Ministry of Ecology and Environment, PRC, National Bureau of Statistics, Ministry of Agriculture and Rural Affairs, PRC. The second national census of pollution sources bulletin. 2020; 13p.

[2] Zhang L B, Liu Y Q, Hao L. Contributions of open crop straw burning emissions to PM2.5 concentrations in China. Environmental Research Letters, 2016; 11(1): 014014. doi: 10.1088/1748-9326/11/1/014014.

[3] Hong J L, Ren L J, Hong J M, Xu C Q. Environmental impact assessment of corn straw utilization in China. Journal of Cleaner Production, 2016; 112(Part2): 1700-1708

[4] Shi Z L, Li X, Wang F, Fang F, Zheng S A, Liu S, et al. Analysis on rural household energy consumption structure in Northeast China. Chinese Journal of Agricultural Resources and Regional Planning, 2017; 38(8): 122-127. (in Chinese)

[5] Tao S, Ru M Y, Du W, Zhu X, Zhong Q R, Li B G, et al. Quantifying the rural residential energy transition in China from 1992 to 2012 through a representative national survey. Nature Energy, 2018; 3(7): 567-573.

[6] Chen Y L, Shen H Z, Smith K R, Guan D B, Chen Y C, Shen G F, et al. Estimating household air pollution exposures and health impacts from space heating in rural China. Environment International, 2018; 119: 117-124.

[7] Chen T, Liao H. The disease burden of indoor air pollution from solid fuel use in China. Asia Pacific Journal of Public Health, 2018; 30(4): 387-395.

[8] Hosseini S E, Wahid M A. Hydrogen production from renewable and sustainable energy resources: Promising green energy carrier for clean development. Renewable and Sustainable Energy Reviews, 2016; 57: $850-866$.

[9] National Development and Reform Commission, National Energy Administration. Plan for clean heating in winter in Northern China (2017-2021). Available: http://www.gov.cn/xinwen/2017/12/20/ content 5248855.htm. Accessed on [2018-12-23].

[10] Su C, Madani H, Palm B. Heating solutions for residential buildings in China: Current status and future outlook. Energy Conversion and Management, 2018; 177: 493-510.

[11] Wang Q, Yang X, Ma N. Heating energy use in China: The current situation, challenges, and possibilities. IOP Conference Series: Earth and Environmental Science. IOP Publishing, 2019; 257(1): 012033. doi: 10.1088/1755-1315/257/1/012033.

[12] Zhang X, Jin Y N, Dai H C, Xie Y, Zhang S Q. Health and economic benefits of cleaner residential heating in the Beijing-Tianjin-Hebei region in China. Energy Policy, 2019; 127: 165-178.

[13] Wang J, Zhou Z, Zhao J, Zheng J, Guan Z. Towards a cleaner domestic heating sector in China: Current situations, implementation strategies, and supporting measures. Applied Thermal Engineering, 2019; 152: 515-531.

[14] Xu H M, Li Y Q, Guinot B, Wang J H, He K L, Ho K F, et al. Personal exposure of PM2.5 emitted from solid fuels combustion for household heating and cooking in rural Guanzhong Plain, northwestern China. Atmospheric Environment, 2018; 185: 196-206.

[15] Zhang S Q, Deng M S, Shan M, Zhou C, Liu W, Xu X Q, et al. Energy and environmental impact assessment of straw return and substitution of straw briquettes for heating coal in rural China. Energy policy, 2019; 128: 654-664.

[16] Sun J, Shen Z X, Zhang Y, Zhang Q, Wang F R, Wang T, et al. Effects of biomass briquetting and carbonization on PM2.5 emission from residential burning in Guanzhong Plain, China. Fuel, 2019; 244: 379-387.

[17] Ren J Q, Yu P X, Xu X H. Straw utilization in China-status and recommendations. Sustainability, 2019; 11(6): 1762 . doi: 10.3390/su11061762.

[18] Ye Y. Research on integrated supply mode of living heat in village-town areas of Heilongjiang based in crop residues. PhD dissertation. Harbin: Harbin Institute of Technology, 2015; 189p.

[19] Zhou Y G, Zhang Z X, Zhang Y X, Wang Y G, Yu Y, Ji F, et al. A comprehensive review on densified solid biofuel industry in China. Renewable and Sustainable Energy Reviews, 2016; 54: 1412-1428.

[20] Ministry of Agriculture and Rural Affairs of the People's Republic of China. Classes and specifications for densified biofuel. NY/T 2909-20163, 2016; 9p. (in Chinese)

[21] IX-CEN. Solid biofuels-Fuel specifications and classes-Part 6: Graded non-woody pellets. BS EN ISO 17225-6:2014, 2014; 7p

[22] IX-CEN. Solid biofuels-Fuel specifications and classes-Part 7: Graded non-woody briquettes. BS EN ISO 17225-7:2014, 2014; 6p.

[23] Shen G. Changes from traditional solid fuels to clean household energies-opportunities in emission reduction of primary PM2.5 from residential cookstoves in China. Biomass and Bioenergy, 2016; 86: 28-35.

[24] Song S Z, Liu P, Xu J, Chong C H, Huang X Z, Ma L W, et al. Life cycle assessment and economic evaluation of pellet fuel from corn straw in China: a case study in Jilin Province. Energy, 2017; 130: 373-381.

[25] Qi J H, Zhao J L, Xu Y, Wang Y J, Han K H. Segmented heating carbonization of biomass: Yields, property and estimation of heating value of chars. Energy, 2018; 144: 301-311.

[26] IX-CEN. Solid biofuels-Fuel specifications and classes-Part 8: Graded thermally treated and densified biomass fuels. ISO 17225-8-2016, 2016; $22 p$.

[27] AQSIQ. China National Standardization Management Committee. Manufactured gas. GB/T 13612-2006, 2006; 4p. (in Chinese)

[28] Sandro N, Agis P, Gojmir R, Vlasta Z, Muslum A. Using pellet fuels for residential heating: A field study on its efficiency and the users' satisfaction. Energy and Buildings, 2019; 184: 193-204.

[29] AQSIQ. China National Standardization Management Committee. General specifications for domestic densified biofuel heating stove. NB/T 34006-2011, 2011; 9p. (in Chinese)

[30] Ministry of Environmental Protection, AQSIQ. Emission standard of air pollutants for boiler. GB 13271-2014, 2014; 7p. (in Chinese)

[31] Ministry of Housing and Urban-Rural Development of the People's Republic of China. Technical code for large and medium-scale biogas 
engineering. GB/T51063-2014, 2014; 65p. (in Chinse)

[32] Zhang L. Study on the comparison and valuation of performance between different heat sources for heating. MS dissertation. Xi'an: Xi'an University of Architecture and Technology, 2010; pp.50-51. (in Chinese)

[33] Ministry of Housing and Urban-Rural Development of the People's Republic of China. Design code for city heating network, CJJ 34-2010, 2010; 153p. (in Chinese)

[34] AQSIQ. China National Standardization Management Committee. The minimum allowable values of energy efficiency and energy efficiency grades of industrial boilers. GB 24500-2009, 2009; 7p. (in Chinese)

[35] AQSIQ. China National Standardization Management Committee. Thermal efficiency and test methods of boilers for daily life. GB/T10820-2011, 2011; 24p. (in Chinese)

[36] AQSIQ. China National Standardization Management Committee. Minimum allowable values of energy efficiency and energy efficiency grades for domestic gas instantaneous water heaters and gas fired heating and hot water combi-boilers. GB-20665-2015, 2015; 8p. (in Chinese)

[37] Chen H J. Application analysis of natural gas heating technology in rural areas of Beijing. MS dissertation. Beijing: Beijing University of Civil Engineering and Architecture, 2018; 66p.

[38] He M, Liu P, Ma L W, Chong C H, Xu L, Xu L, et al. A Systems Analysis of the Development Status and Trends of Rural Household Energy in China. Energies, 2018; 11(7): 1741. doi: 10.3390/en11071741.

[39] He K, Zhang J, Zeng Y. Rural households' willingness to accept compensation for energy utilization of crop straw in China. Energy, 2018; 165: 562-571.

[40] Li J, Chen C, Liu H. Transition from non-commercial to commercial energy in rural China: Insights from the accessibility and affordability. Energy Policy, 2019; 127: 392-403.

[41] Wang F, Wang H Y, Wang Y L. Tests analysis of heating energy consumption and indoor air quality in northeastern rural dwellings of China. Procedia Engineering, 2016; 146: 17-23. 